Mots. Les langages du politique

$81 \mid 2006$

Suisse, laboratoire politique européen ?

\title{
Tuula Vaarakallio, "Rotten to the Core ». Variations of French Nationalist Anti-System Rhetoric
}

Jacques Guilhaumou

\section{OpenEdition}

Journals

Édition électronique

URL : https://journals.openedition.org/mots/734

DOI : $10.4000 /$ mots.734

ISSN : 1960-6001

Éditeur

ENS Éditions

Édition imprimée

Date de publication : 1 juillet 2006

Pagination : 123-125

ISBN : 2-84788-098-4

ISSN : 0243-6450

Référence électronique

Jacques Guilhaumou, "Tuula Vaarakallio, "Rotten to the Core ». Variations of French Nationalist AntiSystem Rhetoric », Mots. Les langages du politique [En ligne], 81 | 2006, mis en ligne le 01 juillet 2008 , consulté le 23 avril 2022. URL : http://journals.openedition.org/mots/734 ; DOI : https://doi.org/ $10.4000 /$ mots. 734

\section{(C) ENS Éditions}


Plusieurs articles abordent cette question de l'éthique sous l'angle historique. Ainsi, par exemple, de l'analyse des médias en Côte d'Ivoire, au Togo ou en Inde où, après la proclamation des indépendances et l'affirmation de l'identité nationale, parfois sous une forme totalitaire, s'amorce une libéralisation: l'organisation des médias et leur rapport à l'éthique est indissociable de cette évolution.

De façon implicite, c'est le modèle occidental qui sous-tend ces approches où l'éthique médiatique est présentée comme étant indissociable des valeurs de liberté individuelle, de concurrence entre médias indépendants, notamment des pouvoirs politiques, etc. Or, c'est bien là une des questions de fond que pose cette interrogation sur l'éthique, et l'on peut regretter que les auteurs de l'étude sur les médias en Malaisie, réfutant le binarisme issu de la domination du modèle occidental « libéral et nettement procapitaliste» (p. 357), ne développent pas davantage cet aspect de leur réflexion.

En effet, et plus largement, si ces études sont individuellement fort intéressantes pour la plupart, on peut regretter l'absence d'une synthèse, ou à tout le moins d'une véritable introduction, qui pose les termes du débat et s'interroge sur la place du modèle occidental et des valeurs qui le sous-tendent - notamment en termes politiques et idéologiques, mais aussi économiques, dimension trop peu prise en compte dans l'ensemble du volume - et sur ses possibles alternatives.

Marlène Coulomb-Gully

Université Toulouse 2, Médiapolis

marlene.coulomb@univ-tlse2.fr

\section{« Rotten to the Core ». Variations of French Nationalist Anti-System Rhetoric Tuula Vaarakallio \\ 2004, Jyväskylä, Université de Jyväskylä, 194 p.}

Dans son ouvrage sur L'illusion populiste (2002, Paris, Berg International), Pierre-André Taguieff s'efforce, au-delà de l'usage flou du terme populisme, d'en proposer une construction idéal-typique qui induit un modèle d'intelligibilité et une typologie des styles politiques populistes, avec leurs opérations rhétoriques spécifiques.

Tuula Vaarakallio nous propose un ouvrage issu d'une thèse de doctorat soutenue à l'université de Jyväskylä (Finlande) sous la direction de Kari Palonen, professeur de sciences politiques, par ailleurs l'un des coorganisateurs du réseau international History of Political and Social Concepts Group et biographe de l'historien Quentin Skinner (2002, Quentin Skinner. History, Politics, Rhetoric, Cambridge, Polity). Au regard de l'approche idéal-typique proposée par 
le politiste P.-A. Taguieff, elle étudie la dimension rhétorique et argumentative au sein de variations majeures du discours national-populiste. De fait, il s'agit d'une analyse discursive d'un corpus bien délimité : une partie des écrits du boulangisme, de Maurice Barrès, de Charles Maurras et du Front national durant la période 1886-2002, soit plus d'un siècle de mouvement nationaliste. Dans la perspective de l'histoire des concepts, T. Vaarakallio s'intéresse à ce que les penseurs nationalistes font en écrivant comme ils le font, et en tant qu'acteurs d'une histoire où ils agissent en disant ce qu'ils disent. Ainsi, elle met l'accent sur les phénomènes de « redescription rhétorique » (Quentin Skinner), c'est-àdire sur les éléments rhétoriques qui contribuent au changement conceptuel à l'intérieur du discours populiste en le constituant en tant que tel, donc en le rendant agissant de lui-même.

Nous sommes ainsi confrontés massivement à une rhétorique dualiste, antithétique, qui prend appui sur une paire philosophique, l'opposition entre l'apparence et la réalité, dont la concrétisation la plus importante est l'opposition entre le pays légal et le pays réel, même si cette distinction n'est pas explicitée en tant que telle dans chaque partie du corpus, par exemple chez $M$. Barrès, et nécessite donc d'être reconstruite à partir d'autres usages antithétiques. Parmi ces usages, les plus saillants concernent les oppositions entre la vanité des luttes politiques et la positivité de la décision compétente dans le respect des traditions, d'une part, entre le verbalisme parlementaire (« le gouvernement de la discussion ») et la politique efficiente dans un cadre autoritaire, d'autre part.

À ce titre, la rhétorique de l'« être contre » suscite une stratégie argumentative qui fait appel à l'essence des choses et base ainsi ses arguments sur une essence déterminée et nationaliste, au nom d'un ordre traditionnel vrai, d'une réalité naturelle. Rhétorique antisystème donc, par sa manière d'opposer la figure du peuple à celle des députés du Parlement, et aussi par sa défense des "petits » contre les « gros ». Demeure-t-elle pour autant dans le cadre plus global de la stratégie du « parler pour et contre » si prégnante au sein même du discours parlementaire, comme le montre Kari Palonen dans ses études en cours sur la conception rhétorique du parlementarisme?

De fait, il demeure une différence essentielle entre le discours nationaliste et le discours parlementaire. La rhétorique parlementaire identifie son adversaire et ses positions dans une joute oratoire visible aux yeux de tous au sein d'un espace de communication réciproque, du moins idéalement. La rhétorique nationaliste nous renvoie conjointement à une politique dont nous ne percevons que la dimension illusoire et à une essence naturelle des choses dont nous n'appréhendons que des effets compensateurs de cette fausse politique.

Entre l'approche rhétorique et l'étude historique, la présente étude de T. Vaarakallio sur les modalités du changement conceptuel au sein du discours nationaliste au cours d'un siècle de vie politique met bien en évidence l'importance de la distinction, dans la recherche d'une politique alternative à la démo- 
cratie parlementaire, entre l'essence de la vraie politique et l'apparence de la fausse politique. À ce titre, la rhétorique nationaliste est plus une rhétorique antisystème qu'une rhétorique antipolitique: elle tend en effet à dévaloriser tant la dynamique démocratique des luttes politiques que la discussion parlementaire au nom d'un unanimisme, d'une cohérence, voire d'une harmonie politiques issues de l'essence naturelle des choses, et à l'encontre de tout pluralisme, de toute alternative et de toute contingence ; elle vise donc à révéler la tendance de la nature à l'ordre et la concrétisation d'un tel ordre social déterminé dans un pouvoir de pure autorité. Il s'agit donc avant tout d'une entreprise de refondation de la politique dans un sens foncièrement conservateur, pour ne pas dire réactionnaire.

Jacques Guilhaumou

Université de Marseille, ENS-LSH, CNRS (Triangle)

guilhaum@newsup.univ-mrs.fr

\section{Le pouvoir des mots. Politique du performatif}

Judith Butler

2004, traduit de l'anglais (Excitable Speech, Routledge, 1997) par Charlotte Nordmann, Paris, Éditions Amsterdam, 287 p.

"Une provocation »: en titrant ainsi sa préface à l'ouvrage de Judith Butler, sa traductrice s'efforce de rendre compte des deux faces, inséparables, du projet de l'auteure. Le pouvoir des mots peut en effet être abordé par son versant théorique - où l'on verra discuter les thèses de Catharine MacKinnon, Mari Matsuda, Shoshana Felman, mais aussi de Louis Althusser, Jacques Derrida ou Pierre Bourdieu - ou par son versant politique, qui s'interroge sur la possibilité de retourner l'efficace des "discours de haine » par une répétition qui en déjoue et en déplace le pouvoir.

Ainsi, si la traduction se veut une «translation » de J. Butler et de sa force polémique, l'ouvrage lui-même se présente, au-delà des débats théoriques sur la performativité, comme un manifeste contre une « censure d'État » inopérante et - en définitive - impossible. La lecture en est ardue et l'effort de la traductrice pour l'enrichir de notes complémentaires ne suffit pas toujours à rendre limpide un texte qui navigue avec une énergie bouillonnante de Nietzsche à Derrida, du concept d'« interpellation » à celui de «forclusion », sans que le format de l'ouvrage permette toujours des éclaircissements suffisants.

Dans l'introduction (intitulée : «De la vulnérabilité linguistique »), J. Butler s'interroge sur le «pouvoir de blesser» de l'invective, qui traduit une relation complexe «de discordance et d'inséparabilité entre le corps et la parole, mais aussi par conséquent entre la parole et ses effets » (p. 37). La question est déjà ici de savoir si les mots peuvent « être disjoints de leur pouvoir de blesser et 